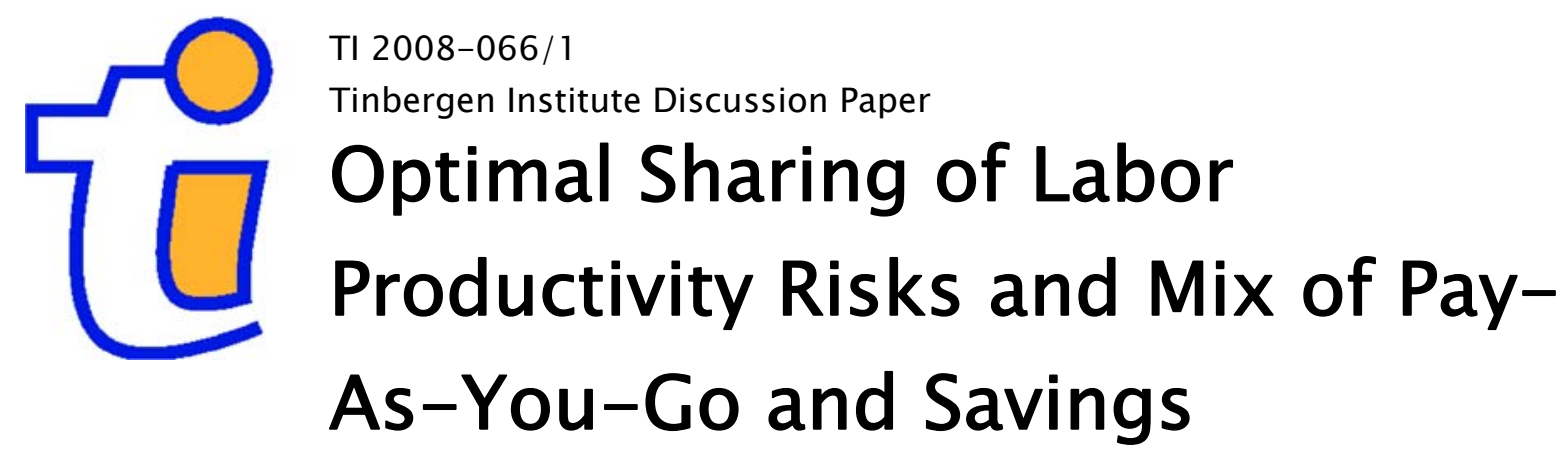

Debora Kusmerski Bilard 


\section{Tinbergen Institute}

The Tinbergen Institute is the institute for economic research of the Erasmus Universiteit Rotterdam, Universiteit van Amsterdam, and Vrije Universiteit Amsterdam.

Tinbergen Institute Amsterdam

Roetersstraat 31

1018 WB Amsterdam

The Netherlands

Tel.: +31(0)205513500

Fax: $+31(0) 205513555$

Tinbergen Institute Rotterdam

Burg. Oudlaan 50

3062 PA Rotterdam

The Netherlands

Tel.: + $31(0) 104088900$

Fax: $+31(0) 104089031$

Most TI discussion papers can be downloaded at http://www.tinbergen.nl. 


\title{
Optimal Sharing of Labor Productivity Risks and Mix of \\ Pay-As-You-Go and Savings
}

\author{
Debora Kusmerski \\ Tinbergen Institute, Amsterdam, the Netherlands * \\ (e-mail: d.e.kusmerskibilard@gmail.com) †
}

\begin{abstract}
The paper addresses two related issues: the optimal intergenerational sharing of labor productivity risks, through a Pay-As-You-Go (PAYG) social security, and the mix of PAYG and savings for retirement provision in a small open economy. It shows that partial contingency of the social security on the stochastic labor productivity is ex ante optimal, when the interest rate is above the expected growth rate of the economy and when the government has a lifetime perspective of the risk exposure. The paper also provides a condition for partial displacement of savings by the PAYG, which is in line with vast empirical evidence.
\end{abstract}

JEL classification: H55, H21, D91.

\section{Introduction}

The social security scheme discussed in this paper is designed for the purpose of optimal intergenerational sharing of labor productivity risks. The scheme features PAYG financing (intergenerational transfers from workers to retirees) and indexation to real wages ${ }^{1}$. Th $\phi$ gersen (1998) showed that both features are necessary for the optimal pooling of labor productivity risks, based on Gordon and Varian (1988). The novelty in the paper is to show that not only the bases of PAYG contributions/benefits should be contingent on the stochastic labor productivity, but also the rates.

The main finding is that, although the net effect of the optimal social security is to shift current labor productivity risks from the young to the elderly via PAYG financing and wage indexation, the optimal covariance between the rate of PAYG and the stochastic growth rate of the economy is negative, which implies partial contingency of the PAYG transfers. Partial contingency, i.e. partial social protection to the elderly, is not only optimal but also a necessary condition for positive PAYG transfers.

The paper provides solutions for the optimal rates of savings and expected PAYG

\footnotetext{
* This version: August 9, 2012.

† I am grateful to Marcel Boumans, John Marshall, Marcos Poplawski Ribeiro and Eytan Sheshinski for helpful discussions, comments and suggestions.

Further comments and suggestions are very welcome.

1 The paper abstracts from monetary issues.
} 
contributions/benefits. In addition, it yields the maximum expected PAYG rate that is compatible with higher saving rate in the PAYG economy, in comparison to the laissez-faire economy. Higher saving rate in the PAYG economy is in line with vast empirical evidence that shows partial displacement of savings by PAYG schemes. ${ }^{2}$

\section{Literature review}

The paper has a normative approach. The literature justifies governmental intervention due to a missing market in the provision of insurance for 'birth-date' events, in an economy of overlapping generations with absence of altruism. The type of risk in consideration is labor productivity risk that is revealed at birth date, i.e. when the young enter the labor market. An insurance is not available at that time because the stochastic outcome is already revealed and, prior that, agents do not insure the unborn because we assume they are not altruistic.

Turning to the concept of optimality and to government's approach, there is no unique criterion for Pareto optimum in stochastic economies. In addition, there is no unified terminology in the literature. We adopt the terminology in Rangel and Zeckhauser (2001), who called the three criteria of Pareto optimum as follows: "ex ante", "interim" and "ex post". From the ex ante perspective, none of the stochastic outcomes are revealed yet. The ex ante approach is associated to the Rawlsian principle of 'ignorance veil'. ${ }^{3}$ From the ex post perspective, all stochastic outcomes are revealed. Finally, from the interim perspective, birth-date stochastic events are revealed, but after-birth events are not. In our context, while the government has an ex ante perspective, the young generation has an interim perspective: they know the realization of their own labor productivity which is a stochastic birth-date event, but they ignore the labor productivity of the next generation which is a stochastic after-birth event in their case. These differences in risk perception and the existence of distinct criteria of optimality turned out to be significant as we see below.

Demange (2002) ruled out the possibility of Pareto improvement through PAYG social security from an interim perspective, in a dynamically efficient economy, if all 'after-birth' events can be insured (sequentially complete markets), or if productive land can be traded without short sales (an infinitely-lived asset that is traded at positive prices in any state of the world). ${ }^{4}$

Nevertheless, sequentially complete markets or productive land are not substitutes for the natural missing market in OLG economies, i.e. the market of ex ante insurance for birth-date events. The reasons for its absence are related to the sequential structure of trade, the finite horizon of agents and the infinite horizon of the

2 See, for instance, Kohl and O'Brien (1998) for a survey of the empirical literature and Bernheim (2002) for a discussion of theoretical aspects.

3 Rawls, John. 1971. A Theory of Justice. Cambridge, Massachusetts: Belknap Press of Harvard University Press. Revised edition, 1999.

${ }^{4}$ In deterministic OLG economies with capital, McCallum (1987) and Homburg (1991) ruled out the possibility of over-accumulation of capital in the presence of land (a fixed, non-reproducible production factor). Richter (1993) extended Homburg (1991) to an economy with uncertain labor income and, in a less general setup than Demange (2002), he also ruled out Pareto improvement via PAYG social security from an interim perspective when productive land is available. 
economy, which are characteristics of deterministic and stochastic OLG economies. In these infinite horizon economies, in every period a generation of finitely-lived agents enters the market; coexistent generations may trade but the unborn can not, as alive generations do not act on their behalf unless they are altruistic. ${ }^{5}$

In sum, this paper assumes that households are not altruistic and the PAYG social security may be ex ante Pareto improving due to the lack of ex ante insurance for the stochastic labor productivity that is revealed at birth date. The government adopts the ex ante approach and its intervention is justified by risk averse households who would like to have ex ante insurance for birth-date events, and by the market failure in the provision of such insurance in the absence of altruism.

Turning to the close-related literature, the paper extends the analyses of optimal intergenerational sharing of labor productivity risks in Enders and Lapan (1982) and Bohn $(1998,2009)$. The three models share a common set of assumptions: the life cycle is represented in two periods and in each period two generations overlap (2x2 OLG model); households are not altruistic; in the laissez-faire economy the only source of uncertainty is the stochastic labor productivity; the stochastic events are independent and identically distributed (i.i.d.) with mean zero.

Enders and Lapan (1982) assumed a closed economy without capital, with labor and where money is the only storage-value device. Workers sell part of their production to the elderly in exchange for money. Prices adjust to the supply of goods and to the existent monetary balances. Prices vary if the supply of goods (the savings of the young) is not constant in consequence of productivity shocks. In this economy, the ex ante optimal intergenerational risk sharing is attained when the saving rate is constant, because then prices and consumption are constant on average (i.i.d., zero-mean shocks). The laissez-faire economy is ex ante optimal when preferences are logarithmic, as the saving rate is constant regardless the income. Otherwise, a compulsory PAYG scheme with constant rate of contribution is ex ante optimal and, in the PAYG economy, household's savings are zero.

Enders and Lapan (1982) showed, in the stochastic economy without capital, that $P A Y G$ social security dominates money as a storage-value device ${ }^{6}$, because in the PAYG economy the government prevents inflation. ${ }^{7}$

Merton (1983) putted forward the idea of PAYG social security as a "quasi-asset". He assumed a closed economy with labor and capital, where there is uncertainty about total output, factor shares and the rate of population growth. He studied the optimal PAYG size for the purpose of intergenerational risk sharing, by framing the problem as an optimal portfolio choice between human and physical capital.

${ }^{5}$ See Geanakoplos (1987) for an analysis of the reasons of sub-optimality and indeterminacy of equilibrium in OLG economies, in comparison to Arrow-Debreu economies, where these problems are absent.

6 The contribution of the young to the social security is not stored or invested, but it is transferred to the elderly (PAYG). Nevertheless, the mandatory character of the scheme assures the young that the next generation will comply and it bails the promise of a future benefit. Therefore, the PAYG can be seen as a storage-value device.

7 Recall that in the deterministic, bargain economy (without labor and capital) of Samuelson (1958), money and social security are equivalent storage-value devices. 
Merton (1983) showed that the PAYG social security is welfare enhancing as it allows the trade of human capital and therefore it diversifies factor-share risks.

Bohn $(1998,2009)$ assumed a closed economy with capital and labor. The young and the elderly generations are simultaneously exposed to labor productivity shocks as in Enders and Lapan (1982), but because the interest rate and wages are correlated. However, there is asymmetry in risk exposure due to less-than-complete capital depreciation. The non-depreciated capital is not a function of the current productivity shock, and it represents a safe asset to be consumed by the elderly. The central planner solution for the ex ante optimal risk sharing involves the correction of the asymmetry in risk exposure between the elderly and the young, through the equalization of the elasticities of consumption with respect to the current shock. In an economy with government, the ex ante optimal risk sharing may be attained by transferring risk from the young to the elderly through intergenerational transfers that are fully indexed to the stochastic labor productivity.

Bohn $(1998,2009)$ wondered why actual fiscal policy instruments (government bonds and the PAYG social security) are not, or not completely, indexed to the stochastic labor productivity when the young are more risk exposed than the elderly. He investigated alternative hypotheses (endogenous labor supply and stochastic capital depreciation), but they could not provide an explanation. He concluded that, unless assuming that the elderly are more risk averse (by including habits in consumption), his model cannot provide a rationale for partial or no contingency of these fiscal instruments, as they shift risk in the wrong direction (from the elderly to the young). ${ }^{8}$

Bohn $(1998,2009)$ showed that, in the stochastic economy with capital, (contingent) $P A Y G$ social security and (non contingent) government debt are not equivalent instruments in the allocation of productivity risks (see also the reviews by Borgmann, 2005, p. 52; and Kaul, 2001, p. 15). ${ }^{9}$

In contrast to Bohn $(1998,2009)$, this paper shows that partial contingency of the social security may be ex ante optimal without assuming that the elderly are more risk averse. The main reason for divergence is that the government has a lifetime perspective of the risk exposure while Bohn $(1998,2009)$ focused on the asymmetry of risk exposure between the coexistent young and elderly generations.

Next, I refer to contributions that paid special attention to the optimal PAYG design in the context of sharing labor productivity risks.

Thøgersen (1998) analyzed, from an ex ante perspective, two alternative PAYG schemes: fixed replacement rate (FR) and fixed contribution rate (FC). In the FR

\footnotetext{
8 Bohn $(1998,2009)$ addresses the U.S. social security debate that took place during the Bush Administration. According to his model, abolishing the wage indexation and investing part of the social security contributions in government bonds would worse the intergenerational allocation of labor productivity risks, because the young would pay, out of their stochastic income, a constant social security contribution and a constant return on government bonds.

See Munnell (2004) for a summary of the main proposal presented in 2001, by 'President Bush's Commission to Strengthen Social Security', and other reform proposals that were in discussion.

${ }^{9}$ Recall that in the deterministic economy with labor and capital of Diamond (1965), internal debt that grows at the rate of the population and social security are equivalent instruments of fiscal policy.
} 
scheme, the pension benefit is a constant proportion of the labor income earned when young. Thus, the pension contribution is indexed to the labor income of the previous generation. Thøgersen (1998) showed that the FR scheme increases the risk exposure of all generations and therefore it lowers welfare. The reason is that it does not spread the risk away from the young and it exposes the young to the risk experienced by the previous generation. In the FC scheme, the pension contribution is a constant proportion of one's own labor income. Thus, the pension benefit is indexed to the labor income of the next generation. Thøgersen (1998) showed that the FC scheme spreads risk away from the young to the elderly. From an ex ante perspective, it pools risks between generations and it increases the welfare of all generations.

In light of Thøgersen (1998), Wagener (2003) reconsidered FR and FC schemes and showed that FR is preferable to FC. He pointed out two main reasons to explain the divergence in results. First, using an interim perspective, Wagener (2003) assumes that the young generation knows the realization of the labor income of the previous generation and its own, i.e. they ignore the labor income of future generations only. Thus, from the interim perspective, the FR is not risky while under the FC scheme the young generation is uncertain about their future pension benefit. Second, Wagener (2003) features intertemporal consumption decision and he accounts for private savings. Assuming that the returns on savings are positively correlated with the stochastic wages, the FR scheme provides insurance because the labor income shocks are independent distributed, while the FC tends to magnifies the risk exposure at old age.

Wagener (2003) also analyzed the problem from an ex ante perspective, since there is no consensus in the literature of stochastic economies regarding the optimality criterion. Under the ignorance veil, he could not rank the two schemes when accounting for private savings and stochastic interest rate. However, when assuming that the interest rate is risk-free and large enough relatively to the PAYG return, Wagener (2003) confirmed the results in Thøgersen (1998), i.e. that FC schemes are preferable to FR.

The contributions of Thøgersen (1998) and Wagener (2003) shed light on actual PAYG schemes, as they fall somewhere in between the two extreme cases of FR and FC. The current paper follows Thøgersen (1998) when adopting an ex ante approach and a social security scheme of FC type. However, it takes a step further by deriving the optimal contingency of the rates of PAYG contributions/benefits instead of assuming constant rates.

Before closing this brief literature review, we turn to recent contributions that considered the optimal mix between PAYG and private savings in the lines of Merton (1983).

Matsen and Thøgersen (2004) considered a problem of optimal portfolio choice, in a small open economy, with no intertemporal consumption decision (the young save the whole income and they consume in the second period only). The young representative agent faces a single decision: how to allocate his income between stocks (yielding a stochastic return) and bonds (a risk-free asset). Matsen and Thøgersen (2004) assumed that wages are subject to permanent stochastic shocks, 
as the growth rate is stochastic. The government decides whether to implement a PAYG social security scheme for the purpose of sharing labor income risks, taken as given the optimal portfolio weights for private savings chosen by the young representative agent.

The analysis takes place under the interim and ex ante perspectives alternatively. Matsen and Thøgersen (2004) provided solutions for the optimal portfolio weights and the optimal PAYG rate. In this setup, the main determinants of the PAYG size are: the expected implicit PAYG return relatively to the risk-free return; the correlation between the implicit PAYG return and the stock market return; the degree of risk aversion. They found that the optimal PAYG rate (size) is smaller under the ex ante approach, since it increases the exposure to labor income risk when the shocks are not transitory.

Thøgersen and Bøhlerengen (2010) extended Matsen and Thøgersen (2004) by considering both cases of shocks in labor income: permanent and transitory. Using an ex ante approach, they found that the distinction regarding the nature of the shocks is relevant for determining the optimal PAYG size. In particular, the desirability of the scheme decreases under permanent labor income shocks.

De Menil et al. (2005) considered the optimal PAYG size and the optimal mix between PAYG and funded savings, in a model that features intertemporal allocation of consumption. They provided numerical solutions and simulated the model using real data to infer the stochastic properties of labor and capital incomes.

The current paper assumes that the labor productivity shocks are permanent and that the return on savings is risk free (government bonds). The solutions for the ex ante optimal policy and the interim optimal savings shed further light on the determinants of the optimal PAYG-savings mix. In addition, it shows the maximum expected PAYG rate that is compatible with higher savings in the PAYG economy. 


\section{The model}

The model is described in five sections. The conclusions, appendixes and references follow after. Section 1 contains assumptions about the labor force, technology, factor prices, risk exposure and dynamic efficiency. Section 2 describes preferences and the behaviour of households. Section 3 defines the government's problem and its approach. Section 4 determines the ex ante optimal social-security policy and the interim optimal savings in equilibrium. Section 5 illustrates the model with the numerical analysis.

\section{Preliminary assumptions}

\subsection{Labor force}

The labor supply is given exogenously. The labor force evolves according to:

$$
L_{t}=\left(1+n_{t}\right) L_{t-1}
$$

where, $L_{t}$ is the size of the young generation alive at time $t$ in the small open economy.

\subsection{Technology}

Labor productivity is augmented by $A_{t}$, the labor efficiency per worker, according to the Cobb-Douglas labor-augmenting function: $Y_{t}=K_{t}^{\alpha}\left(A_{t} L_{t}\right)^{1-\alpha}$.

The labor efficiency is exogenously given and it depends, among other factors, on the state of the technology. It follows a stochastic process:

$$
A_{t}=\left(1+g_{t}\right) A_{t-1}=\left(1+g+\epsilon_{t}\right) A_{t-1} ; 0 \leq\left|\epsilon_{t}\right|<g \text { and } E\left[\epsilon_{t}\right]=0 \quad \forall t ;
$$

where, $1+g$ is the expected growth rate of the marginal labor productivity per worker or the growth rate of labor efficiency in the long run; $\epsilon_{t}$ is a stochastic disturbance at time $t$.

Unexpected technological changes, for instance, may cause unexpected variations in labor productivity, but we assume that younger generations are more productive.

The stochastic disturbances are independent and identically distributed (i.i.d.), with expected value of zero.

The growth rate of the economy is given by the growth rates of the labor force and the marginal labor productivity per worker:

$$
1+\nu_{t}=\left(1+n_{t}\right)\left(1+g_{t}\right) .
$$

\subsection{Production and factor prices}

There is a number $I$ of small open economies characterized by free mobility of capital and labor and by perfect competition. They determine the open-economy equilibrium of factor prices. 
Capital markets clear at the end of the previous period, i.e. the interest rate and the aggregate capital stock in period $t$ are determined at the end of period $t-1$.

The total supply of capital in period $t$ is the sum, over the $I$ economies, of the aggregate savings in period $t-1$. It is a function of the saving rate $\left(\widetilde{s}_{i, t-1}\right)$ and the aggregate labor income $\left(w_{t-1} A_{i, t-1} L_{i, t-1}\right)$ in period $t-1$ :

$$
K_{t}^{S}=\sum_{i=1}^{I} \widetilde{s}_{i, t-1}\left(w_{t-1} A_{i, t-1} L_{i, t-1}\right)
$$

where, $i=1, \ldots, I$ is an index for the open economies; $w_{t-1} A_{i, t-1}$ is the 'efficiency' wage and $L_{i, t-1}$ is the labor force in economy $i$ in period $t-1$.

Firms maximize expected profits by choosing at the end of period $t-1$ the optimal capital intensity, i.e. the capital per effective worker, for period $t$. We assume that the $I$ economies share the same Cobb-Douglas technology $\left(\alpha_{i}=\alpha, \forall i \in I\right)$ and expectations. Thus, the capital intensity is equal among them $\left(k_{i, t}=k_{t}, \forall i \in I\right)$ :

$$
\max _{k_{t}} k_{t}^{\alpha}-\left(\delta+E_{t-1}\left[r_{t}\right]\right) k_{t}-E_{t-1}\left[w_{t}\right] ;
$$

where, $k_{t}^{\alpha}$ is the product per effective worker according to the Cobb-Douglas laboraugmenting function; $\delta$ is the rate of capital depreciation; $E_{t-1}\left[r_{t}\right]$ and $E_{t-1}\left[w_{t}\right]$ are the expectations in period $t-1$ about factor prices in period $t$.

The capital intensity at time $t$ is a function of the given technology and the expectations at time $t-1: k_{t}=f\left(\alpha ; E_{t-1}\left[r_{t}\right], E_{t-1}\left[w_{t}\right], E_{t-1}\left[A_{t} L_{t}\right]\right)$, where $E_{t-1}\left[A_{t} L_{t}\right]$ is the expected total effective labor force.

The total demand for capital is:

$$
K_{t}^{D}=k_{t} E_{t-1}\left[A_{t} L_{t}\right] .
$$

The rate of interest in period $t\left(r_{t}\right)$, determined at the end of period $t-1$, satisfies the equilibrium condition of the capital market:

$$
k_{t} E_{t-1}\left[A_{t} L_{t}\right]=\sum_{i=1}^{I} \widetilde{s}_{i, t-1}\left(w_{t-1} A_{i, t-1} L_{i, t-1}\right) .
$$

The competitive wage in period $t\left(w_{t}\right)$ is determined at the end of period $t-1$, given the condition of perfect competition: $w_{t}=k_{t}^{\alpha}-\left(\delta+r_{t}\right) k_{t}$.

The supply of effective labor in period $t$ is known at the beginning of period $t$ :

$$
A_{t} L_{t}=\sum_{i=1}^{I}\left(1+g_{i, t}\right)\left(1+n_{i, t}\right) A_{i, t-1} L_{i, t-1} .
$$

Firms hire workers at the point where the marginal labor productivity per effective worker $(1-\alpha) k_{t}^{\alpha}$ equals the competitive wage $w_{t}$.

Labor markets clear at the beginning of the period, when the effective labor force is revealed. Labor movements occur until the equilibrium is established at the full employment level, given that the stochastic disturbances are expected to be zero and they are independent also across the $I$ countries.

Table 1 summarizes the timing of uncertainty resolution and decision making, in period $t$, in the small open economy $i$. (We omit the country index $i$ hereafter). 
Table 1: Timing of events, in one period, in the small open economy

\begin{tabular}{|c|c|}
\hline Beginning of period $t$ & End of period $t$ \\
\hline a) The stochastic event $\left(\varepsilon_{t}\right)$ is revealed. & $\begin{array}{l}\text { e) Firms pay for the use of production } \\
\text { factors: }\left(\delta+r_{t}\right) K_{t} \text { and } w_{t} A_{t} L_{t}\end{array}$ \\
\hline $\begin{array}{l}\text { b) Workers supply inelastically the } \\
\text { effective labor input }\left(A_{t} L_{t}\right) \text {. }\end{array}$ & $\begin{array}{l}\text { f) Young households supply the } \\
\text { aggregate savings, given the }\end{array}$ \\
\hline $\begin{array}{l}\text { c) Firms hire workers, given the marginal } \\
\text { labor productivity per effective worker } \\
\text { revealed at the beginning of period } t \text {, }\end{array}$ & $\begin{array}{l}\text { expectations about the interest rate } \\
\text { in period } t+1 \text {. }\end{array}$ \\
\hline $\begin{array}{l}\text { and the competitive wage determined } \\
\text { at the end of period } t-1 \text {. }\end{array}$ & $\begin{array}{l}\text { g) Firms demand the stock of capital for } \\
\text { period } t+1 \text {, given the expectations about } \\
\text { factor prices and the effective labor force. }\end{array}$ \\
\hline $\begin{array}{l}\text { d) Labor movements occur until } \\
\text { the market clears at the full } \\
\text { employment level, given the } \\
\text { 'white noise' in labor productivity. }\end{array}$ & $\begin{array}{l}\text { h) Factor prices }\left(r_{t+1}, w_{t+1}\right) \text { are } \\
\text { determined, according to the equilibrium } \\
\text { condition for the capital market and } \\
\text { perfect competition. }\end{array}$ \\
\hline
\end{tabular}

After determining production and factor prices within a period, we consider now the dynamics of the economy in the long run. Since we want to avoid the possibility of dynamic inconsistency of government's policy (as it will become clear later), we make the assumption of a 'stochastic steady state' as defined below.

\section{Definition 1}

The small open economy is in the stochastic steady state, where the growth rate of the labor force $(1+n)$, the interest rate $(1+r)$ and the capital intensity ( $k)$ are constant; whereas the growth rates of labor efficiency $\left(1+g_{t}\right)$ and the economy $\left(1+\nu_{t}\right)$ are stochastic.

\subsection{Risk exposure}

From the ex ante perspective, both generations are risk exposed. The young are exposed because, although the 'competitive' wage is constant $(w)$, the 'efficiency' wage $\left(w A_{t}\right)$ is stochastic. The elderly are exposed because their assets are a function of the stochastic efficiency wage received when young: $w A_{t-1}$. Both stochastic variables, $A_{t-1}$ and $A_{t}$, are not revealed yet from the the ex ante perspective.

The elderly and the young coexistent generations are asymmetrically risk exposed in the laissez-faire economy because they are not exposed to a simultaneous shock. However, since the shocks are i.i.d. and the economy is in the stochastic steady state, all generations are equally risk exposed from a lifetime perspective. Under these assumptions, the government does not aim to equalize the risk exposure between the coexistent generations like the central planner in Bohn $(1998,2009)$, but rather 
it uses the asymmetry in risk exposure within a period in order to attain a better risk sharing from a lifetime perspective.

In Bohn $(1998,2009)$, both generations are exposed to the current labor productivity shock because the economy is closed. However, the elderly is less risk exposed because of less-than-complete capital depreciation $(\delta<1)$. The non-depreciated capital is not a function of the current productivity shock, and thus it represents a safe asset to be consumed by the elderly. In contrast, in the current framework, lessthan-complete capital depreciation plays no special role because the interest rate is risk free. Thus, we assume complete capital depreciation after a period $(\delta=1)$.

\subsection{Dynamic efficiency}

The economy is expected to be strictly dynamically efficient, i.e. the expected rate of economic growth (the expected PAYG return) is below the rate of interest (the return on savings). Thus, intergenerational transfers are costly, as households forgo a higher return when making the compulsory PAYG contribution. We define the 'expected PAYG premium' as the present value of the lifetime expected consumption loss from marginal changes in the PAYG rates, due to the difference in expected returns between private savings and the PAYG scheme. Enders and Lapan (1982) and Bohn $(1998,2009)$ abstracted from the PAYG premium: the first by assuming an economy without capital and the latter, an economy with a central planner. ${ }^{10}$

\section{Households}

Households make decisions when they are young. They have an interim perspective, i.e. in any period $t$ the young know their own efficiency $\left(A_{t}\right)$ and their rate of PAYG contribution $\left(\theta_{t}\right)$, but the values of the next generation $\left(A_{t+1}\right.$, and $\left.\theta_{t+1}\right)$ are unknown, as they are stochastic and will be revealed in period $t+1$.

\subsection{The household's problem}

Households are not altruistic and they do not leave bequests. The representative young household maximizes the expected lifetime utility from consumption:

$$
E_{t}\left[U_{t}\left(c_{1, t} ; c_{2, t+1}\right)\right]=u\left(c_{1, t}\right)+\frac{T_{2}}{T_{1}} \rho E_{t}\left[u\left(c_{2, t+1}\right)\right] ;
$$

where, $u(\cdot)$ is the instantaneous utility from consumption; $\rho \leqslant 1$ is the rate of time preference; $0<T_{2} / T_{1} \leqslant 1$ is the subjective expected time spent in retirement relatively to the working period.

The parameter $T_{2} / T_{1}$ is introduced to reflect that savings depend on the length of time that households expect to spend in retirement. The standard two-period OLG

10 In appendix, the Box 'The expected PAYG premium' discusses the costs of intergenerational transfers in different institutional setups: central planned economy, closed and small-open dynamically efficient economies. 
model is the special case of $T_{2} / T_{1}=1$, which is analyzed in the numerical analysis in comparison with the case of $T_{2} / T_{1}<1$. The parameter $T_{2} / T_{1}$ would be unnecessary in a multi-period model, where the number of working and retirement periods may differ explicitly. In contrast, ignoring it in the two-period model is likely to bias savings. In addition, although we do not model the interaction between retirement and savings as pointed out in Feldstein (1974), alternative values of $T_{2} / T_{1}$ can be interpreted as exogenous changes in retirement patterns and/or expected longevity. Savings are a positive function of $T_{2} / T_{1}$ as shown later.

During the working period, the budget constraint faced by households is:

$$
c_{1, t}=\left[\left(1-\theta_{t}\right) w_{t}-s_{t}\right] A_{t}
$$

where, $c_{1, t}$ is the consumption in the first period; $\theta_{t}$ is the contingent rate of PAYG contribution at time $t$; and $s_{t} A_{t}$ are the household's savings.

During the retirement,

$$
c_{2, t+1}=\left[\theta_{t+1}\left(1+\nu_{t+1}\right) w_{t+1}+\left(1+r_{t+1}\right) s_{t}\right] A_{t} ;
$$

where, $c_{2, t+1}$ is the consumption in the second period; $\theta_{t+1}\left(1+\nu_{t+1}\right) w_{t+1} A_{t}$ is the contingent PAYG benefit received at time $t+1$. Notice that $\left(1+\nu_{t+1}\right)=$ $(1+n)\left(1+g_{t+1}\right)$, where $(1+n)$ is the steady-state growth rate of the labor force and $\left(1+g_{t+1}\right)$ is the indexation to the stochastic labor productivity of the next generation.

The PAYG transfers are contingent because the bases $\left(w_{t} A_{t}\right.$ and $\left.w_{t+1} A_{t+1}\right)$ and rates $\left(\theta_{t}\right.$ and $\left.\theta_{t+1}\right)$ of PAYG contribution/benefit depend on the stochastic disturbances in labor productivity.

The young determines the optimal saving $\left(s_{t}\right)$ that maximizes the expected lifetime utility in (4), given the budget constraints in equations (5)-(6). Differentiating (4) with respect to $s_{t}$ and using (5)-(6), it yields the optimal consumption path or Euler equation:

$$
\frac{T_{2}}{T_{1}} \rho\left(1+r_{t+1}\right) E_{t}\left[u^{\prime}\left(c_{2, t+1}\right)\right]=u^{\prime}\left(c_{1, t}\right) .
$$

\subsection{Quadratic preferences}

Households' preferences are represented by the quadratic utility function:

$$
u\left(c_{i, \tau}\right)=c_{i, \tau}-\frac{a_{t}}{2} c_{i, \tau}^{2} ; c_{i, \tau} \in\left\{c_{1, t} ; c_{2, t+1}\right\} \text { and } a_{t}>0 .
$$

The quadratic function provides tractability but at the cost of two well-known drawbacks: a) the marginal utility can become negative as consumption increases, in contrary to rational choice; b) stationary preferences $\left(a_{t}=a\right)$ display increasing risk aversion, in contrary to the empirical evidence that supports constant relative risk aversion. Since younger generations are expected to be wealthier by assumption, 
they would be more risk averse under stationary preferences. Nevertheless, a proper choice of the parameter $a_{t}$ allows for different attitudes towards risk and, as shown at the end of this subsection, the choice made below implies quasi-constant relative risk aversion and it bounds the marginal utility to non-negative values.

\section{Definition 2}

The free parameter in the quadratic function is non stationary and it is calibrated as the inverse of the efficiency wage: $a_{t} \equiv 1 / w_{t} A_{t}$.

\subsubsection{The best response}

Given the preferences, we can determine the 'best response' function, i.e. the interim optimal savings of the young given the social security policy.

Computing the marginal utilities from the quadratic function (8), substituting them and the budget constraints (5)-(6) into the Euler equation (7), it yields: ${ }^{11}$

$$
s_{t} A_{t}=\left[\begin{array}{c}
m p s_{t}\left(1-\theta_{t}\right) w_{t}+\frac{m p c_{t}-\left(1+r_{t+1}\right) m p s_{t}}{\left(1+r_{t+1}\right) a_{t} A_{t}} \\
-m p c_{t} \frac{E_{t}\left[\theta_{t+1}\left(1+\nu_{t+1}\right)\right] w_{t+1}}{1+r_{t+1}}
\end{array}\right] A_{t} ;
$$

where, $m p s_{t} \equiv \frac{1}{1+\frac{T_{2}}{T_{1}} \rho\left(1+r_{t+1}\right)^{2}}$ is the marginal propensity to save and $m p c_{t} \equiv$ $1-m p s_{t}$ is the marginal propensity to consume.

Substituting for $a_{t} \equiv 1 / w_{t} A_{t}$, substituting for $E_{t}\left[\theta_{t+1}\left(1+\nu_{t+1}\right)\right]$ using that $\operatorname{Cov}\left[\theta_{t+1},\left(1+\nu_{t+1}\right)\right]=E_{t}\left[\theta_{t+1}\left(1+\nu_{t+1}\right)\right]-\bar{\theta}(1+\nu)$ and assuming that the economy is in the stochastic steady state, it yields the best-response function:

$$
s_{t} A_{t}=\left[\begin{array}{c}
m p s\left(1-\theta_{t}\right)+\frac{m p c-(1+r) m p s}{1+r} \\
-m p c\left(\frac{\bar{\theta}(1+\nu)+\operatorname{Cov}\left[\theta_{t+1},\left(1+\nu_{t+1}\right)\right]}{1+r}\right)
\end{array}\right] w A_{t} ;
$$

where, $\bar{\theta}$ is the expected PAYG rate; $\operatorname{Cov}\left[\theta_{t+1},\left(1+\nu_{t+1}\right)\right]$ is the covariance between the rate of PAYG and the growth rate of the economy in the next period.

The first term in (9) is the marginal propensity to save out of the disposable income. The last term is the anticipation of the expected PAYG benefit for present consumption. The term $m p c-(1+r) m p s$ is peculiar to quadratic preferences and we call it the 'self-insurance'. It is not a function of the contingent social security, i.e. it does not represent precautionary savings. ${ }^{12}$

We assume that households alive at time $t$ know the following policy variables: the contingent rate of PAYG contribution revealed at time $t\left(\theta_{t}\right)$; the expected

11 A technical appendix showing step-by-step the computations of the paper is available under request.

12 Blanchard and Fisher (1989), chapter 6, show that among the HARA class of utility functions: quadratic, CARA and CRRA; the quadratic is the only function that does not display prudence. Thus, it does not generate precautionary savings. 
rate paid by the next generation $(\bar{\theta})$, as the government announces it ex ante. In addition, although the rate of growth in the next period $\left(\nu_{t+1}\right)$ and the rate of PAYG contribution of the next generation $\left(\theta_{t+1}\right)$ are unknown at time $t$; households know the covariance between them, since the government 'anchors' expectations when announcing ex ante a constant covariance.

Thus,

$$
E_{t}\left[\theta_{t+1}\right]=E_{-\infty}\left[\theta_{t+1}\right] \equiv \bar{\theta} \quad \forall t ;
$$

where, $E_{t}$ denotes expectation in period $t$ and $E_{-\infty}$ denotes ex ante expectation.

In addition,

$$
\operatorname{Cov}\left[\theta_{t+1},\left(1+\nu_{t+1}\right)\right] \equiv \operatorname{Cov}[\theta,(1+\nu)] \quad \forall t .
$$

Notice that the covariance is unitless as both arguments of $C o v$ are rates: the PAYG rate and the growth rate of the economy.

We assume also that:

$$
\frac{\operatorname{Cov}\left[\theta_{t+1}, A_{t+1}\right]}{E_{-\infty}\left[A_{t+1}\right]} \equiv \frac{\operatorname{Cov}[\theta,(1+\nu)]}{1+\nu} \forall t .
$$

The solution of the government's problem, in Section 4 , yields $\bar{\theta}$ and $\operatorname{Cov}[\theta,(1+\nu)]$. The assumptions made above avoid unnecessary uncertainty about the contingent social security policy, as they pin expectations down.

Substituting the optimal savings in (9) into the budget constraints (5)-(6), it yields the optimal consumption rates:

$$
\begin{gathered}
\frac{c_{1, t}}{w A_{t}}=\left\{\begin{array}{c}
m p c\left[\left(1-\theta_{t}\right)+\frac{\bar{\theta}(1+\nu)+\operatorname{Cov}\left[\theta_{t+1},\left(1+\nu_{t+1}\right)\right]}{1+r}\right] \\
-\frac{m p c-(1+r) m p s}{1+r}
\end{array}\right\}, \\
\frac{c_{2, t+1}}{w A_{t}}=\left\{\begin{array}{c}
(1+r) m p s\left(1-\theta_{t}\right)+\theta_{t+1}\left(1+\nu_{t+1}\right) \\
-m p c\left[\bar{\theta}(1+\nu)+\operatorname{Cov}\left[\theta_{t+1},\left(1+\nu_{t+1}\right)\right]\right]+m p c-(1+r) m p s
\end{array}\right\} .
\end{gathered}
$$

The expected value of (12) at time $t$ is:

$$
\frac{E_{t}\left[c_{2, t+1}\right]}{w A_{t}}=\left\{\begin{array}{c}
(1+r) m p s\left[\left(1-\theta_{t}\right)+\frac{\bar{\theta}(1+\nu)+\operatorname{Cov}\left[\theta_{t+1},\left(1+\nu_{t+1}\right)\right]}{1+r}\right] \\
+m p c-(1+r) m p s
\end{array}\right\} .
$$

\subsubsection{Risk aversion degrees and rational choice with non-stationary preferences}

We close section 2 with a discussion about the consequences of calibrating the free parameter of the quadratic utility function in terms of attitudes towards risk and rational choice. Table 2, in appendix, contains a summary of the household 
behavior, according to different values assigned to the parameter $a_{t}$ in the utility function $u(c)=c-\frac{a_{t}}{2} c^{2}$.

Since we assume that $a_{t} \equiv 1 / w A_{t}$, the utility function has the functional form: $u\left(c_{i, \tau}\right)=c_{i, \tau}-\frac{1}{2} \frac{c_{i, \tau}^{2}}{w A_{t}} ; c_{i, \tau} \in\left\{c_{1, t} ; c_{2, t+1}\right\}$. The coefficient of absolute risk aversion is: $-\frac{u^{\prime \prime}\left(c_{i, \tau}\right)}{u^{\prime}\left(c_{i, \tau}\right)}=\frac{1}{\{1-[\cdot]\} w A_{t}}$, where [.] represent the optimal consumption rates $\frac{c_{1, t}}{w A_{t}}$ and $\frac{E_{t}\left[c_{2, t+1}\right]}{w A_{t}}$ from equations (11) and (13). The coefficient of relative risk aversion is: $-\frac{u^{\prime \prime}\left(c_{i, \tau}\right)}{u^{\prime}\left(c_{i, \tau}\right)} c_{i, \tau}=\frac{[\cdot]}{1-[\cdot]}$. Thus, $a_{t} \equiv 1 / w A_{t}$ implies decreasing absolute risk aversion between generations, as $A_{t+1}>A_{t} \forall t$, and quasi-constant relative risk aversion because $[\cdot]$ is constant except by the contingent rate of PAYG contribution. Further, from equations (11) and (13), the marginal utilities are positive in the laissez-faire economy $\left(\theta_{t}=0 \forall t\right): u^{\prime}\left(c_{1, t}\right)=\frac{m p c}{1+r}$ and $u^{\prime}\left(c_{2, t+1}\right)=m p s$. Thus, we can conclude that they are positive also in the PAYG economy $\left(\theta_{t}>0 \forall t\right)$, as the expected PAYG premium is positive. Hence, the choice of $a_{t} \equiv 1 / w A_{t}$ overcomes the two drawbacks of the quadratic utility function.

The assumption of $a_{t} \equiv 1 / w A_{t}$ holds throughout the analysis, but Table 2 shows the implications of alternative values for $a_{t}$. The coefficients of absolute and relative risk aversion are: a) increasing, when $a_{t} \equiv a$ (stationary preferences); b) decreasing and quasi-constant respectively, when $a_{t} \equiv 1 / w A_{t} ;$ c) decreasing when $a_{t} \equiv 1 / w A_{t}^{2}$; d) increasing when $a_{t} \equiv 1 / w$. In concerning rational choice, except for $a_{t} \equiv 1 / w A_{t}$, the signs of the marginal utilities depend on $a_{t}$ and/or $A_{t}$ and they should be bounded for yielding a positive value.

\section{The government}

The reason for governmental intervention is the existence of an uninsurable risk, namely the stochastic labor efficiency, which is revealed when the young generation joins the labor market. At that time, insurance is not available because the outcome is common knowledge. Ex ante insurance is also not available because households are not altruistic and they do not insure unborn generations.

The government adopts an ex ante perspective of the risk-sharing problem, under the assumption that risk averse households would like to have ex ante insurance for birth events. Subsection 1.4 defined the risk exposure in the laissez-faire economy: elderly's assets are a function of the stochastic labor income that is revealed at time $t-1$, whereas the stochastic labor income of the young generation is revealed at time $t$. From the ex ante perspective both events are not revealed yet, and thus the young and the elderly are exposed to risk.

\subsection{The government's problem}

The government of the small open economy $i$ is considering to implement a PAYG social security in period $t .{ }^{13}$ Provided that the transfers from the young to the

13 Although natives of the country $i$ may work in any of the $I$ countries, they would contribute to and receive benefits from the scheme in country $i$. The paper ignores international coordination issues, and the isolated decision of the small open economy $i$ has no effect on factor prices. 
elderly are positive, the first elderly generation retiring under the scheme is always better off because of 'windfall' benefits, as no prior contributions were made. Thus, the government leaves this generation out of the analysis.

From the ex ante view, the first young and all future generations are unborn. They are equally risk exposed along the lifetime because the productivity shocks are i.i.d. and the economy is in the stochastic steady state. In addition, they are also (quasi) equally relative-risk averse. Consequently, the government assigns equal weights to these generations, and its objective function is the ex ante lifetime utility of a representative generation. ${ }^{14}$

The government chooses ex ante a sequence of contingent PAYG rates $\left(\theta_{t}\right.$ and $\left.\theta_{t+1}\right)$ that solves the following problem:

$$
\underset{\theta_{t}, \theta_{t+1}}{\operatorname{Max}} E_{-\infty}\left[u\left(c_{1, t}^{*}\right)+\rho E_{t}\left[u\left(c_{2, t+1}^{*}\right)\right]\right]
$$

where, $c_{1, t}^{*}$ and $c_{2, t+1}^{*}$ are the optimal consumption functions in equations (11)$(12) \cdot{ }^{15}$

The PAYG budget is balanced in each period, i.e. the aggregate benefits are equal to the aggregate contributions in any time $t:\left(1+\nu_{t}\right) \theta_{t} w A_{t-1}=(1+n) \theta_{t} w A_{t}$, according to the budget constraints of households in equations (5)-(6). Thus, government's problem is solved as an unconstrained maximization problem.

Differentiating the government's objective function (14) with respect to $\theta_{t}$ and $\theta_{t+1}$; using the Euler equation (7), the consumption functions in (11)-(12) and the constant-covariance assumption in (10); it yields the first-order conditions:

$$
\begin{gathered}
E_{-\infty}\left[E_{t}\left[u^{\prime}\left(c_{2, t+1}\right)\right] A_{t}\right]=0 ; \\
E_{-\infty}\left[E_{t}\left[u^{\prime}\left(c_{2, t+1}\right) A_{t+1}\right]\right]=0 .
\end{gathered}
$$

\section{Equilibrium}

The timing of the decisions and the interaction between the decision makers can be described as a 'Stackelberg leadership' game, i.e. the leader (the government) moves first and the follower (households) moves subsequently. The government intervenes once for all. The time evolving per se does not change the optimal policy, i.e. it

14 In appendix, Box 'Social welfare weights and dynamic consistency of the policy' works out the government problem as the maximization of a sum of discounted lifetime utilities. It shows that, under the conditions of our problem, the resulting first-order conditions are equivalent to those obtained by maximizing the lifetime utility of a representative generation.

15 We assume that the social security provides insurance for longevity risks. Consequently, the government does not take $T_{2} / T_{1}$ as a weight for the second-period utility in (14), in contrast to households in (4). In any case, leaving $T_{2} / T_{1}$ in the objective function of the government would not change the results, as it washes out during the derivation of the first-order conditions of the government. Nevertheless, the government takes into account the optimal consumption functions of households, which are functions of $T_{2} / T_{1}$ through the marginal propensities to save and to consume. 
is dynamically consistent, as we assumed the stochastic steady state. The government knows the expectations of households and their best response function, and it sets the social security policy before households determine savings. Households are informed about the government's policy and its commitment to it in the long run. Households have no means of deviating, because the participation in the PAYG scheme is mandatory.

The next subsections determine the ex ante optimal policy and the interim optimal savings in equilibrium.

\subsection{The ex ante optimal policy}

Substituting the quadratic function, with $a_{t} \equiv 1 / w A_{t}$, into the first-order condition (15); substituting for $E_{t}\left[c_{2, t+1}\right]$ from equation (13); using the assumptions about the covariance in (10)-(10a); using that $m p c+m p s=1$; it yields the expected optimal rate of PAYG contribution as a function of the covariance:

$$
\bar{\theta}=-\frac{1}{1-\frac{1+\nu}{1+r}} \frac{1}{1+r}-\frac{\operatorname{Cov}[\theta,(1+\nu)]}{1+v} ;
$$

where, $1-\frac{1+\nu}{1+r}$ is the expected 'golden rule gap' or the 'rate of PAYG premium'; $\operatorname{Cov}[\theta,(1+\nu)]$ is the covariance between the contingent PAYG rate and the growth rate of the economy.

The ex ante optimal covariance is obtained by using the first-order condition (16), substituting for $c_{2, t+1}$ from equation (12) and for $\bar{\theta}$ from (17) and using the same assumptions made above:

$$
\frac{\operatorname{Cov}[\theta,(1+\nu)]}{1+v}=-\frac{\operatorname{Cov}[P A Y G,(1+g)]}{(1+r) m p s} ;
$$

where, $\operatorname{Cov}[P A Y G,(1+g)] \equiv \frac{\operatorname{Cov}\left[\left(1+\nu_{t+1}\right) \theta_{t+1} A_{t},\left(1+g_{t+1}\right)\right]}{E_{-}\left[A_{t+1}\right]} \forall t$.

The PAYG benefit that is paid at time $t+1$ to the generation born at time $t$ is: $\left(1+\nu_{t+1}\right) \theta_{t+1} w A_{t}$. Thus, $\operatorname{Cov}\left[\left(1+\nu_{t+1}\right) \theta_{t+1} A_{t},\left(1+g_{t+1}\right)\right]$ is the covariance between the PAYG benefit and the growth rate of labor efficiency at time $t+1$. From the assumption made in (10), $\operatorname{Cov}[P A Y G,(1+g)]$ is constant.

Substituting (18) into (17) yields the expected optimal rate of PAYG contribution:

$$
\bar{\theta}=-\frac{1}{1-\frac{1+\nu}{1+r}} \frac{1}{1+r}+\frac{\operatorname{Cov}[P A Y G,(1+g)]}{(1+r) m p s} .
$$




\subsection{The conditions for a solution}

We can see from equation (17) that, given a positive expected rate of PAYG premium, a positive expected rate of PAYG implies a negative covariance, i.e.: $1-\frac{1+\nu}{1+r}>0$ and $\bar{\theta}>0 \Rightarrow \operatorname{Cov}[\theta,(1+\nu)]<0 .{ }^{16}$ In addition, from equation (18), $\operatorname{Cov}[\theta,(1+\nu)]<0 \Rightarrow \operatorname{Cov}[P A Y G,(1+g)]>0$.

By assumption, the bases of PAYG contribution/benefit are fully indexed to the labor efficiency and that shifts risk from the young to the elderly; but the negative covariance between the PAYG rate and the growth rate of the economy partially offsets the indexation effect and it provides partial social protection to the elderly.

From the ex ante perspective, the young benefit from making a positive transfer to the elderly because they transfer risky income and anticipate part of the expected benefit for present consumption. The elderly benefit from pooling risks with the young, as they are exposed to a previous and independent shock that affected their labor income. In other words, the indexation of the bases of PAYG contribution/benefit reduces the volatility of ex ante consumption in both periods of the life cycle.

Nevertheless, equation (17) shows that, if the covariance between the PAYG rate and the growth rate of the economy is not negative, or its magnitude is not significant; a negative rate of PAYG contribution is optimal, which means that dynamic efficiency dominates the risk-sharing motive. Notice that negative PAYG transfers would make the first young and all future generations better off when $v<r$, because instead of incurring the PAYG premium they would earn it. However, it is not ex ante Pareto optimal, as it would reduce the welfare of the first elderly generation.

Finally, equation (18) shows that the indexation effect should be dominant, i.e. the covariance between the PAYG benefit and the growth rate of the labor efficiency should be positive.

In conclusion, the optimal scheme actually shifts current labor productivity risk from the young to the elderly, but the income that is transferred is partially contingent to that risk.

Lemma 1 summarizes the conditions for a solution.

Lemma 1

Given that the small open economy is expected to be strictly dynamically efficient $(v<r)$, the necessary and sufficient conditions for a positive expected PAYG rate $(\bar{\theta}>0)$ are: $\left|\frac{\operatorname{Cov}[\theta,(1+\nu)]}{1+v}\right|>\frac{1}{1-\frac{1+\nu}{1+r}} \frac{1}{1+r}$ and $\operatorname{Cov}[P A Y G,(1+g)]>\frac{m p s}{1-\frac{1+\nu}{1+r}}$.

Proof

See equations (17) and (17a).

16 I am grateful to Professor Eytan Sheshinski for the suggestion of allowing for contingent PAYG rates, which turned to be fundamental for finding a solution to the risk-sharing problem. 
Theorem 1 states the main results.

Theorem 1

Given,

(i) the PAYG social security implies an expected positive premium $\left(1-\frac{1+\nu}{1+r}>0\right)$;

(ii) the bases of PAYG contribution/benefit are fully indexed to the stochastic labor income, and they shift current labor productivity risk from the young to the elderly. Then, unless there are ex ante welfare gains also from providing partial social protection at the old age, through a negative covariance between the PAYG rate and the growth rate of the economy $(\operatorname{Cov}[\theta,(1+\nu)]<0)$; dynamic efficiency dominates the risk-sharing motive, i.e. the expected optimal rate of PAYG contribution $(\bar{\theta})$ is non positive. In case of a solution $(\bar{\theta}>0)$, the ex ante optimal social security ultimately shifts current labor productivity risk from the young to the elderly, since the optimal covariance between the PAYG benefit and the growth rate of labor efficiency is positive $\left(\operatorname{Cov}\left[\left(1+\nu_{t+1}\right) \theta_{t+1} A_{t},\left(1+g_{t+1}\right)\right]>0\right)$.

Proof

See equations (17)-(18).

As discussed in subsection 2.2.2, the coefficient of relative risk aversion is quasiconstant between generations because of the calibration of the free parameter of the quadratic function with a non-stationary value $\left(a_{t} \equiv 1 / w_{t} A_{t} \forall t\right)$. Hence, our finding that partial contingency of the PAYG transfers is ex ante optimal it is not related to higher risk aversion at the old age as argued in Bohn $(1998,2009)$.

As a final remark about equation (17a), it is evident the existent trade-off between dynamic efficiency and risk sharing: $\bar{\theta}$ has a negative component that involves the PAYG premium and $\bar{\theta}$ has a positive component that involves risk, $\frac{\operatorname{Cov}[P A Y G,(1+g)]}{(1+r) m p s}$, which is discussed below.

We saw that a solution for $\bar{\theta}$ implies that $\operatorname{Cov}[P A Y G,(1+g)]$ is positive and that risks are ultimately shifted from the young to the elderly. $\bar{\theta}$ is increasing in $\operatorname{Cov}[P A Y G,(1+g)]$ but it is clearly decreasing in $(1+r)$ mps and, as argued in the proposition below, this last term measures the risk exposure of the elderly.

Proposition 1

From the ex ante perspective, the stochastic perturbation $\epsilon_{t-1}$ in the labor income $w A_{t-1}$ is not revealed yet. The accumulated assets of the elderly alive at time $t$ are: $(1+r) s_{t-1} A_{t-1}$ and they are a function of the stochastic labor income received when young $\left(w A_{t-1}\right)$, according to equation (9). Thus, in the government's perspective the elderly is risk exposed. We argue that the return rate of savings times the marginal propensity to save, i.e. $(1+r)$ mps, is an ex ante marginal rate of risk exposure of the elderly.

Hence, the optimal policy takes into consideration the risk exposure of the elderly through the negative covariance between the contingent rate of PAYG and the growth rate of the economy: $\operatorname{Cov}[\theta,(1+\nu)]<0$, and through an expected PAYG rate $(\bar{\theta})$ that is decreasing in the proxy for elderly's risk exposure: $(1+r)$ mps. 


\subsection{The contingent rates of PAYG contribution}

A further characterization of the optimal policy is possible through the analysis of the ex-post PAYG benefit. ${ }^{17}$

The deviation of the ex post PAYG benefit from the average, in period $t+1$, is:

$$
B_{t+1}-\bar{B}=\left[\theta_{t+1}\left(1+\nu_{t+1}\right)-\bar{\theta}(1+\nu)\right] w A_{t} ;
$$

where, $B_{t+1} \equiv \theta_{t+1}\left(1+\nu_{t+1}\right) w A_{t}$ is the (ex post) PAYG benefit received at time $t+1$ by a representative household from generation $t ; \bar{\theta}$ is given by (17a).

Since $1+\nu_{t+1}=(1+n)\left(1+g_{t+1}\right)=(1+n)\left(1+g+\epsilon_{t+1}\right)$ in the stochastic steady state, according to the assumptions in (2)-(3); rewrite $B_{t+1}-\bar{B}$ as:

$$
B_{t+1}-\bar{B}=(1+n)\left[\theta_{t+1} \epsilon_{t+1}+(1+g)\left(\theta_{t+1}-\bar{\theta}\right)\right] w A_{t} .
$$

The deviation is decomposed into two sources. One is due to the indexation of the base of the benefit to the stochastic productivity of the young: $(1+n) \theta_{t+1} \epsilon_{t+1}$; and the other is due to the contingency of the PAYG rate: $(1+v)\left(\theta_{t+1}-\bar{\theta}\right)$. The deviation due to the indexation has the same sign of the shock $\left(\epsilon_{t+1}\right)$, whereas $\left(\theta_{t+1}-\bar{\theta}\right)$ has the opposite sign according to the ex ante optimal covariance. Since the indexation effect should be dominant, $B_{t+1}-\bar{B}$ has the same sign of $\epsilon_{t+1}$. We consider below the three possible outcomes: $\epsilon_{t+1} \lessgtr 0$, and the respective intervals for $\theta_{t+1}$ that are consistent with the ex ante optimal policy.

The first case is:

$$
\theta_{t+1}=\bar{\theta} \text { for } \epsilon_{t+1}=0 \text {. }
$$

The second case is a positive shock. Thus, the PAYG rate should be below the average rate $\left(\theta_{t+1}<\bar{\theta}\right)$ and, together with the condition of a dominant indexation effect: $\theta_{t+1} \epsilon_{t+1}>-(1+g)\left(\theta_{t+1}-\bar{\theta}\right)$, it provides the following interval for $\theta_{t+1}$ :

$$
\frac{1+g}{1+g+\epsilon_{t+1}} \bar{\theta}<\theta_{t+1}<\bar{\theta} \text { for } \epsilon_{t+1}>0 \text {. }
$$

The last case is:

$$
\bar{\theta}<\theta_{t+1}<\frac{1+g}{1+g+\epsilon_{t+1}} \bar{\theta} \text { for } \epsilon_{t+1}<0 .
$$

We assumed in equation (2) that the stochastic disturbances are smaller than $g$ in magnitude $\left(0 \leq\left|\epsilon_{t}\right|<g, \forall t\right)$, otherwise an adverse shock would imply that younger generations could be less productive.

17 I thank Professor John Marshall for raising an issue concerning the ex-post PAYG benefit, in the seminar of the Risk Theory Society at the Colorado State University, which originated this section. 


\subsection{The interim optimal savings}

In this subsection we determine the interim optimal savings in equilibrium in the PAYG and laissez-faire economies.

Setting $\theta_{t}=0$ in equation (9) and denoting the laissez-faire by the superscript $l f$, it yields:

$$
\frac{s_{t}^{l f} A_{t}}{w A_{t}}=\frac{m p c}{1+r} .
$$

Substituting for $\bar{\theta}$ from equation (17) into the best-response function in (9) and using the assumption of constant covariance in (10), it yields the interim optimal saving rate in the PAYG equilibrium:

$$
\frac{s_{t} A_{t}}{w A_{t}}=-m p s * \theta_{t}+\frac{m p c}{1+r} * \frac{1}{1-\frac{1+\nu}{1+r}} .
$$

The difference in saving rates is:

$$
\frac{s_{t} A_{t}}{w A_{t}}-\frac{s_{t}^{l f} A_{t}}{w A_{t}}=\frac{m p c}{1+r}\left[\frac{1}{1-\frac{1+\nu}{1+r}}-1\right]-m p s * \theta_{t} .
$$

Proposition 2

Given that the small open economy is expected to be strictly dynamically efficient $(v<r)$, the condition for higher savings in the PAYG economy is: $\theta_{t}<$ $\frac{m p c}{(1+r) m p s}\left[\frac{1}{1-\frac{1+\nu}{1+r}}-1\right] \forall t$.

As mentioned before, vast empirical evidence shows partial displacement of private savings by PAYG schemes, i.e. higher saving rate in the PAYG economy but decreasing total savings.

\subsection{Static comparative analysis of the ex ante savings}

In the laissez-faire economy, the saving rate $\left(\frac{s_{t}^{l f} A_{t}}{w A_{t}}\right)$ is not affected by ceteris paribus changes in the expected growth rates of labor force $(1+n)$ or labor efficiency $(1+g)$. A ceteris paribus change in the steady-state interest rate $(1+r)$ has an ambiguous effect on private savings, due to income and substitution effects that have opposite signs. A ceteris paribus change in one of the preference parameters, the rate of time preference $(\rho)$ or the expected time spent in retirement relatively to working years $\left(T_{2} / T_{1}\right)$, leads the saving rate to change in the same direction.

In the static comparative analysis of the PAYG economy, we take ex ante expectations of equation $(9 \mathrm{a})$. The derivatives of the ex ante saving rate $\left(E_{-\infty}\left[\frac{s_{t} A_{t}}{w A_{t}}\right]\right)$ are therefore a function of the expected PAYG rate $(\bar{\theta})$ and its derivatives. Let $\bar{\theta}$ tend to zero and hold it constant while varying one of the steady-state exogenous variables. Then, ceteris paribus changes in $(1+n)$ or $(1+g)$ cause the ex ante saving rate to change in the same direction. Similarly to the laissez-faire economy, the sign of the derivative with respect to the interest rate is ambiguous and the signs with respect to the preference parameters are positive. 


\section{Numerical analysis}

This section evaluates numerically: a) the conditions for a solution for the ex-ante optimal PAYG rate $(\bar{\theta}>0)$, summarized in Lemma $1 ;$ b) the saving rate in the laissez-faire economy in equation $(20)$; c) the ex ante saving rate in the PAYG economy, obtained by taking expectations of equation (9a); d) the condition for higher total savings in the PAYG economy, in Proposition (2).

The exogenous variables, i.e. the interest and expected growth rates, are expressed per period (35 years) and in an annual basis. In the baseline, the annual values are: the rate of interest is 3.5 percent, the expected rates of growth of labor force and labor efficiency are both 0.5 percent. The preference parameters in the baseline are: the subjective discount rate is $\rho=0.3$, the subjective expected years in retirement relatively to working years are $T_{2} / T_{1}=15 / 35$.

In Tables 3 and 4 (in the Appendix), we let the ex-ante PAYG rate tend to zero $(\bar{\theta} \rightarrow 0)$ and we compute the maximum ex ante saving rate in the PAYG economy. In Table $5, \bar{\theta}$ varies and we compute the correspondent ex ante saving rates.

Table 3 shows the equilibrium and the sensitivity analyses for alternative values of the interest and expected growth rates. In the baseline, the expected rate of PAYG premium is 57.5 percent, which means that for any $\$ 1$ in PAYG contribution, households forgo $\$ 0.575$ due to the higher expected return on private savings. The conditions for a solution $(\bar{\theta}>0)$ are: the absolute value of $\frac{\operatorname{Cov}[\theta,(1+\nu)]}{1+v}$ should be higher than 0.52 and $\beta \equiv \operatorname{Cov}[P A Y G,(1+g)]$ should be above 0.72 . The saving rate in the laissez-faire economy is 18 percent. The maximum ex ante saving rate in the PAYG economy is 31 percent. The condition for higher total savings in the PAYG economy demands an ex-ante PAYG rate $(\bar{\theta})$ that does not exceed 32 percent.

In Table 3, first the expected rate of growth of labor efficiency varies (alternative values to the baseline are in bold). Decreases in $g$ (from 0.5 to 0.25 , or to 0 percent) increase the PAYG premium (from 57.5 to 61 , or to 64.3 percent). The values of the minimum covariances for a solution $(\bar{\theta}>0)$, i.e. the minimum absolute value for $\frac{\operatorname{Cov}[\theta,(1+\nu)]}{1+v}$ falls (from 0.52 to 0.49 , or to 0.47 ) and the minimum value of $\beta \equiv \operatorname{Cov}[P A Y G,(1+g)]$ falls (from 0.72 to 0.67 , or to 0.64 ). Changes in $g$ or $n$ have no effect on the optimal saving rate of the laissez-faire economy, since they do not affect the marginal propensities to save or to consume. Decreases in $g$ lower the maximum saving rate in the PAYG economy (from 31 to 29 , or to 27 percent). Finally, the maximum values of the ex-ante PAYG rate that are compatible with higher total savings fall (from 32 to 27 , or to 24 percent). Increases in $g$ (from 0.5 to 1 , or to 1.5 percent) have the opposite effects than described above. Variations in the rate of growth of the labor force $(n)$ have exactly the same effects of varying $g$ for the variables under consideration, as both affect the expected growth rate of the economy in the same way. Thus, they are omited.

Second, the interest rate varies. A static comparative analysis shows that the marginal propensity to save changes in the opposite direction of the interest rate, i.e. the income effect is dominant. However, the derivatives of the saving rates are ambiguous in the laissez-faire and PAYG economies due to the opposite income and substitution effects. In Table 3, when the interest rate falls (from an annual rate of 
3.5 to 3 , or to 2.5 percent), the marginal propensity to save increases (from 0.41 to 0.5 , or to 0.58 ), the saving rate in the laissez-faire economy remains constant (18 percent), the maximum ex ante saving rate in the PAYG economy increases (from 31 to 36 , or to 44 percent), the maximum value of the ex-ante PAYG rate that is compatible with higher total savings increases (from 32 to 37 , or to 45 percent). In regarding the covariance values for a solution: the minimum absolute value for $\frac{\operatorname{Cov}[\theta,(1+\nu)]}{1+v}$ increases (from 0.52 to 0.72 , or to 1.05 ) and the minimum value of $\beta \equiv \operatorname{Cov}[P A Y G,(1+g)]$ increases (from 0.72 to 1 , or to 1.44). When the interest rate increases (from an annual rate of 3.5 to 4 , or to 4.5 percent), the marginal propensity to save decreases (from 0.41 to 0.33 , or to 0.26 ), the saving rate in the laissez-faire economy falls (from 18 to 17 , or to 16 percent), the maximum ex ante saving rate in the PAYG economy falls (from 31 to 26 , or to 23 percent), the maximum value of the ex-ante PAYG rate that is compatible with higher total savings falls (from 32 to 28 , or to 26 percent). In regarding the covariance values for a solution: the minimum absolute value for $\frac{\operatorname{Cov}[\theta,(1+\nu)]}{1+v}$ falls (from 0.52 to 0.40 , or to 0.31 ) and the minimum value of $\beta \equiv \operatorname{Cov}[P A Y G,(1+g)]$ falls (from 0.72 to 0.52 , or to 0.38 ).

Table 4 shows the equilibrium and the sensitivity analyses for the preference parameters. First, we varied the subjective expected years in retirement relatively to working years $\left(T_{2} / T_{1}\right)$ from $15 / 35$ to 1 , where 1 is the conventional assumption in the $2 \times 2$ OLG model. Consequently, the saving rate in the laissez-faire economy increases from 18 to 23 percent and the maximum ex ante saving rate in the PAYG economy goes from 31 to 40 percent. From the static comparative analysis we know that, although the marginal propensity to save (mps) is decreasing in $T_{2} / T_{1}$, the saving rate in the laissez-faire economy and the maximum ex ante saving rate in the PAYG economy are increasing functions of it. The values of the minimum covariances for a solution $(\bar{\theta}>0)$, i.e. the minimum absolute value for $\frac{\operatorname{Cov}[\theta,(1+\nu)]}{1+v}$ is not a function of $T_{2} / T_{1}$ whereas the minimum value of $\beta \equiv \operatorname{Cov}[P A Y G,(1+g)]$ is decreasing in $T_{2} / T_{1}$. Finally, the maximum values of the ex-ante PAYG rate that are compatible with higher total savings are increasing in $T_{2} / T_{1}$. The effects of the other alternative value of $T_{2} / T_{1}(10 / 35)$ is easily seen from the table.

Second, we varied the subjective discount rate $(\rho)$ from 0.3 to 0.7 and it turned out to have exactly the same effect of increasing $T_{2} / T_{1}$ from $15 / 35$ to 1 . The effects of the alternative value of $\rho(0.5)$ is easily seen from the table.

Table 5 shows the ex ante saving rates in the PAYG economy, given alternative values of the expected PAYG rate and the baseline values of the exogenous variables. The ex ante saving rate decreases steadily as the expected PAYG rate increases. When the expected PAYG rate rises above 32 percent, savings fall below the rate of the laissez-faire economy (18 percent). 


\section{Conclusions}

The paper extended previous analyses of the optimal intergenerational sharing of labor productivity risks to a small open and dynamically efficient economy. Departing from Bohn $(1998,2009)$ in assuming: a) intergenerational transfers are costly, b) the overlapping generations are not exposed to simultaneous shocks, c) there is equal risk exposure from a lifetime perspective and, (quasi) constant relative risk aversion between generations; the risk-sharing problem has changed in a fundamental way. In contrast to Bohn $(1998,2009)$ who analyzed the asymmetry in risk exposure between the overlapping generations within a period, we took a lifetime perspective of the risk exposure.

We found theoretical support for providing partial social protection at the old age, through positive intergenerational transfers (from the young to the elderly) that are partially contingent on the stochastic labor efficiency: full indexation of the bases of PAYG contribution/benefit (by assumption), but negative (optimal) covariance between the contingent PAYG rate and the stochastic growth rate of the economy. The indexation of the bases shifts risk from the young to the elderly, whereas the negative covariance does the opposite. The net effect is partial contingency of the PAYG benefits on the stochastic labor productivity, but the indexation effect should prevail, as we found that the optimal covariance between the PAYG benefit and the growth rate of labor efficiency is positive. Partial social protection at the old age is optimal, without assuming that the elderly generation is more risk averse than the young. Further, it is a necessary condition for positive PAYG transfers when the return on savings is above the expected growth rate of the economy (the expected PAYG return).

The paper characterizes the ex ante optimal policy by providing: a) solutions for the ex ante optimal PAYG rate $(\bar{\theta})$ and for the optimal covariance between the PAYG rate and the growth rate of the economy $(\operatorname{Cov}[\theta,(1+\nu)])$; b) the optimal sign of the covariance between the PAYG benefit and the growth rate of labor efficiency $(\operatorname{Cov}[P A Y G,(1+g)])$; c) well-defined intervals for the contingent PAYG rates $\left(\theta_{t}, \theta_{t+1}, \ldots\right)$, according to the realization of the stochastic disturbances $\left(\epsilon_{t}\right.$, $\left.\epsilon_{t+1}, \ldots\right)$. However, the functional forms of the ex post variables, i.e. the contingent PAYG rates and $\operatorname{Cov}[P A Y G,(1+g)]$, are not determined and multiple solutions may be admissible. ${ }^{18}$

In regarding the optimal combination of PAYG and savings, the paper provides solutions for the interim optimal saving rates in the laissez-faire and PAYG economies. It also provides the maximum PAYG rate that is compatible with higher savings, since the empirical evidence shows partial displacement of private savings by PAYG schemes, i.e. higher saving rate in the PAYG economy.

18 Recall that we differentiated the government's objective function with respect to two policy instruments: two subsequent contingent rates of PAYG $\left(\theta_{t}, \theta_{t+1}\right)$. Then, we obtained two first-order conditions that provided solutions for the ex ante optimal PAYG rate $(\bar{\theta})$ and for the ex ante optimal covariance between the PAYG rate and the growth rate of the economy $(\operatorname{Cov}[\theta,(1+\nu)])$. However, they are a function of $\operatorname{Cov}[P A Y G,(1+g)]$. 


\section{Appendix}

\section{Box: The expected PAYG premium}

In our small open economy, from the interim perspective of the young alive at time $t$, the present value of the expected PAYG premium is the sum of changes in current and expected consumption caused by marginal changes in current and expected PAYG rates:

$$
\frac{\partial c_{1, t}}{\partial \theta_{t}}+\frac{\partial c_{1, t}}{\partial \bar{\theta}}+\frac{1}{1+r}\left[\frac{\partial E_{t}\left[c_{2, t+1}\right]}{\partial \theta_{t}}+\frac{\partial E_{t}\left[c_{2, t+1}\right]}{\partial \bar{\theta}}\right]=-\left[1-\frac{1+\nu}{1+r}\right] w A_{t} ;
$$

where, $1-\frac{1+\nu}{1+r}$ is the expected 'golden rule gap' ( $\nu$ is the rate of growth in the economy and $r$ is the rate of interest); $c_{1, t}$ and $E_{t}\left[c_{2, t+1}\right]$ are determined in equations (11) and (13).

The expected rate of PAYG premium equals the expected 'golden rule gap', which is positive when the economy is expected to be strictly dynamically efficient $(\nu<r)$.

In a central planned economy, intergenerational transfers are not costly because we expect the economy to be at the 'golden rule': $r=\nu$, or at the 'modified golden rule': $1+r=(1+\nu)(1+\lambda)$, where $1+\lambda \geqslant 1$ is a social discount rate. These are equilibrium points associated with maximum consumption and maximum discounted social welfare respectively, in the one-sector neoclassic growth model (see Blanchard and Fischer 1989, p. 45).

In a closed economy, Diamond (1965) showed that public debt reduces the capital stock in two ways: 1) by lowering the disposable income and, consequently savings, because of the debt service (interest payments on internal or external debt); 2) by substituting debt for capital in household's portfolio (internal debt only). The reduction of capital stock has feedback effects through lower wages that further reduce savings and thus the capital supply. Hence, since public debt reduces the rate of capital accumulation, it may be Pareto improving only when the economy is dynamically inefficient, i.e. when the economy is accumulating capital in excess. The conclusions in Diamond (1965) apply to the PAYG social security in deterministic closed economies, since in these economies PAYG schemes and internal debt are equivalent (see an exemplification of this equivalence in Borgmann 2005, p. 8-11).

In small open economies, since there are free capital flows and the interest rate is exogenously determined, the PAYG social security has no consequences for the capital stock. ${ }^{a}$ Nevertheless, the PAYG contribution represents compulsory savings with expected lower return when $\nu<r$, i.e. the social security claim is a dominated asset. In the absence of a risk-sharing motive, there are only corner solutions for the optimal PAYG rate: 0 when $\nu<r$; or 1 otherwise, provided that the young generation can borrow on the account of the future PAYG benefit according to the lower open-economy interest rate.

${ }^{a}$ The current paper abstracts from the external equilibrium of the small open economy, after the implementation of the PAYG scheme. See Persson (1985) for the extension of the OLG model in Diamond (1965) to a small open economy and the current account adjustment following an one-time increase in the public debt. 


\section{Box: Social welfare weights and dynamic consistency of the policy $(1 / 2)$}

Suppose that the government's objective function at time $t$ is the sum of the discounted lifetime utilities of generations $t, t+1, \ldots, T-1$ seen from ex ante:

$$
E_{-\infty}\left[S W_{t}\right]=E_{-\infty}\left[\sum_{\tau=t}^{T-1} \lambda_{t, \tau}\left\{u\left(c_{1, \tau}^{*}\right)+\rho E_{\tau}\left[u\left(c_{2, \tau+1}^{*}\right)\right]\right\}\right] ;
$$

where, $E_{-} \infty$ denotes ex ante expectations; $E_{\tau}$ are the expectations in period $\tau ; \lambda_{t, \tau}=$ $\left(\frac{1}{1+\lambda}\right)^{\tau-t}$ is the social welfare weight assigned at time $t$ to generation $\tau ; 1+\lambda \geqslant 1$ is the constant discount rate of the government; $\rho \leq 1$ is the subjective discount rate of households; $u(\cdot)$ is the instantaneous utility from consumption; $c_{1, \tau}^{*}$ and $c_{2, \tau+1}^{*}$ are the optimal consumption functions of households.

The government chooses a sequence of PAYG contribution rates $\left(\theta_{t} ; \theta_{t+1} \ldots \theta_{T-1}\right)$ that maximizes the objective function in $\left(a^{\prime}\right)$, which yields the following first-order conditions:

$$
\begin{aligned}
& \frac{\partial E_{-\infty}\left[S W_{t}\right]}{\partial \theta_{t}}=E_{-\infty}\left[u^{\prime}\left(c_{1, t}^{*}\right) \frac{\partial c_{1, t}^{*}}{\partial \theta_{t}}+\rho E_{t}\left[u^{\prime}\left(c_{2, t+1}^{*}\right) \frac{\partial c_{2, t+1}^{*}}{\partial \theta_{t}}\right]\right]=0 . \\
& \frac{\partial E_{-\infty}\left[S W_{t}\right]}{\partial \theta_{\tau}}=E_{-\infty}\left[\begin{array}{c}
\frac{\lambda_{t, \tau-1}}{\lambda_{t, \tau}} \rho E_{\tau-1}\left[u^{\prime}\left(c_{2, \tau}^{*}\right) \frac{\partial c_{2, \tau}^{*}}{\partial \theta_{\tau}}\right] \\
+u^{\prime}\left(c_{1, \tau}^{*}\right) \frac{\partial c_{1, \tau}^{*}}{\partial \theta_{\tau}}+\rho E_{\tau}\left[u^{\prime}\left(c_{2, \tau+1}^{*}\right) \frac{\partial c_{2, \tau+1}^{*}}{\partial \theta_{\tau}}\right]
\end{array}\right]=0 ; \\
& \tau=t+1, . ., T-1
\end{aligned}
$$

- The intertemporal condition

Substituting for $u^{\prime}\left(c_{1, t}^{*}\right)$, from the Euler equation (7) into $\left(b^{\prime}\right)$ :

$$
\begin{aligned}
& \frac{\partial E_{-\infty}\left[S W_{t}\right]}{\partial \theta_{t}} \\
= & \rho E_{-\infty}\left[\frac{T_{2}}{T_{1}}\left(1+r_{t+1}\right) E_{t}\left[u^{\prime}\left(c_{2, t+1}^{*}\right)\right] \frac{\partial c_{1, t}^{*}}{\partial \theta_{t}}+E_{t}\left[u^{\prime}\left(c_{2, t+1}^{*}\right) \frac{\partial c_{2, t+1}^{*}}{\partial \theta_{t}}\right]\right]=0 .
\end{aligned}
$$

Assuming that $\frac{\partial c_{2, t+1}^{*}}{\partial \theta_{t}}$ is known at time $t$ although $c_{2, t+1}^{*}=$ $f\left(A_{t+1}, \theta_{t+1} ; A_{t}, \theta_{t}\right)$ and $A_{t+1}$ and $\theta_{t+1}$ are unknown:

$\frac{\partial E_{-\infty}\left[S W_{t}\right]}{\partial \theta_{t}}=\rho E_{-\infty}\left[\left(\frac{T_{2}}{T_{1}}\left(1+r_{t+1}\right) \frac{\partial c_{1, t}^{*}}{\partial \theta_{t}}+\frac{\partial c_{2, t+1}^{*}}{\partial \theta_{t}}\right) E_{t}\left[u^{\prime}\left(c_{2, t+1}^{*}\right)\right]\right]=0$.

Assuming that $\frac{\partial c_{1, t}^{*}}{\partial \theta_{t}}$ and $\frac{\partial c_{2, t+1}^{*}}{\partial \theta_{t}}$ are linear functions of $w_{t} A_{t}$ (the labor income), it yields:

$$
E_{-\infty}\left[E_{t}\left[u^{\prime}\left(c_{2, t+1}^{*}\right)\right] A_{t}\right]=0 .
$$

which is the same first-order condition obtained in (15). 


\section{Box: Social welfare weights and dynamic consistency of the policy $(2 / 2)$}

- The intergenerational conditions

Given, (i) the welfare weights are dynamically consistent, e.g. $\lambda_{t, \tau}=\left(\frac{1}{1+\lambda}\right)^{\tau-t}$ (see Heijdra and van der Ploeg 2002, p. 629-631); (ii) two assumptions: a) stochastic steady state, b) i.i.d. and zero-mean shocks. The intertemporal condition in $\left(b^{\prime}\right)$ holds for any $\tau$. In addition, since $\lambda \geqslant 0$, the intergenerational conditions in $\left(c^{\prime}\right)$ reduce to:

$$
E_{-\infty}\left[E_{\tau-1}\left[u^{\prime}\left(c_{2, \tau}^{*}\right) \frac{\partial c_{2, \tau}^{*}}{\partial \theta_{\tau}}\right]\right]=0 \quad \forall \tau
$$

Using the assumption of constant covariance in (10), assuming that $\frac{\partial c_{2, \tau}^{*}}{\partial \theta_{\tau}}$ is a linear function of $w A_{\tau}$ (the labor income of the next generation) and setting $\tau=t+1$ yield:

$$
E_{-\infty}\left[E_{t}\left[u^{\prime}\left(c_{2, t+1}^{*}\right) A_{t+1}\right]\right]=0 .
$$

which is the same first-order condition obtained in (16).

Hence, the objective function in $\left(a^{\prime}\right)$ yields the same first-order conditions than those obtained from (14). Under the assumptions made above (stochastic steady state and i.i.d. shocks) that imply equal risk exposure between generations from a lifetime perspective, plus the assumption of (quasi) equal risk aversion; we conclude that dynamic consistency of the policy implies equal treatment of generations $(\lambda=0)$. Therefore, we formulated government's problem as one of maximizing the lifetime utility of a representative generation.

Notice that $\frac{\partial c_{2, \tau}^{*}}{\partial \theta_{\tau}}>0$ and, without the assumptions in (ii), the first-order conditions in $\left(c^{\prime}\right)$ are for $\tau=t+1, \ldots, T-1$ :

$$
\begin{aligned}
& E_{-} \infty\left[u^{\prime}\left(c_{1, \tau}^{*}\right) \frac{\partial c_{1, \tau}^{*}}{\partial \theta_{\tau}}+\rho E_{\tau}\left[u^{\prime}\left(c_{2, \tau+1}^{*}\right) \frac{\partial c_{2, \tau+1}^{*}}{\partial \theta_{\tau}}\right]\right] \\
= & -(1+\lambda) \rho E_{-\infty}\left[E_{\tau}\left[u^{\prime}\left(c_{2, \tau}^{*}\right) \frac{\partial c_{2, \tau}^{*}}{\partial \theta_{\tau}}\right]\right]<0 ;
\end{aligned}
$$

i.e. the ex ante marginal-lifetime-utility loss, due to the PAYG contribution of the young at time $\tau$, corresponds to the marginal utility gain of the elderly, adjusted by the social and subjective weights $(\lambda$ and $\rho$ ). In contrast, under stationarity assumptions, the ex ante lifetime-marginal-utility loss is zero, according to $\left(b^{\prime}\right){ }^{a}$

${ }^{a}$ Blanchard and Fisher (1989, p. 102) refer to the arbitrarity of social discounting $\left(\lambda_{t, \tau} \neq 1\right)$ as a parameter that is "unrelated to preferences as captured by the individual utility function". Diamond (1965, p. 1128) assumed that the economy is in the steady state, before defining the objective function of the central planner as the lifetime utility of a representative generation. Similarly, in the current paper, the government defines its objective function as the lifetime utility of a representative generation, given that the generations are equally risk exposed and (quasi) equally relative-risk averse. 
Table 2: Summary of quadratic preferences

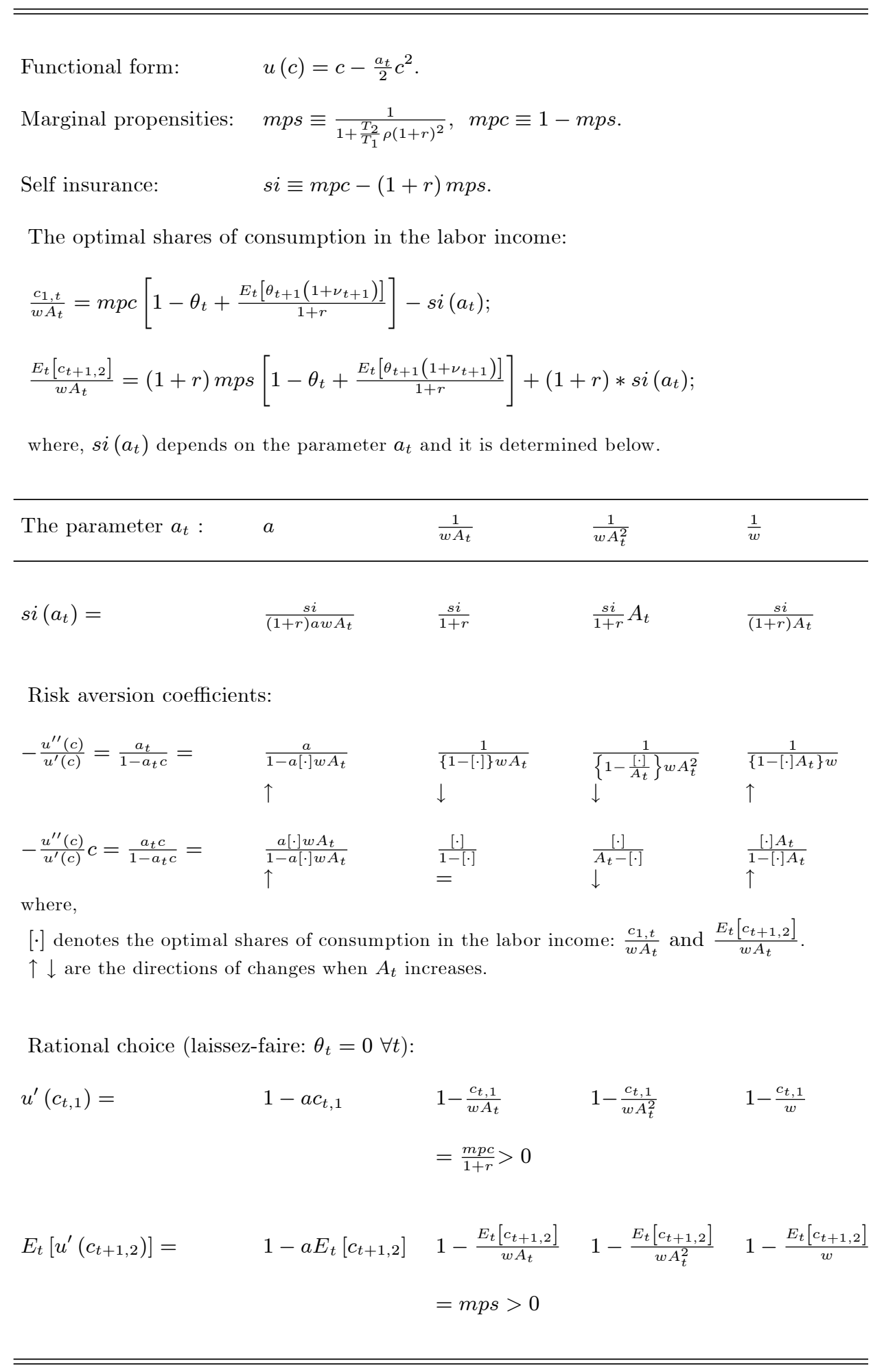


Table 3: The equilibrium with quadratic preferences $\left(a_{t}=1 / w A_{t} ; \rho=0.3 ; T_{2} / T_{1}=15 / 35\right)$

Sensitivity analysis of the interest and growth rates

\begin{tabular}{|c|c|c|c|c|c|c|c|c|c|c|}
\hline \multirow{2}{*}{$\begin{array}{r}\text { I } \\
\text { p } \\
1+r\end{array}$} & \multicolumn{3}{|c|}{$\begin{array}{l}\text { Interest and growth rates } \\
\left.\text { er period ( } T_{1}=35 \text { years }\right) \\
\text { annual }\end{array}$} & \multirow{2}{*}{$\begin{array}{l}\text { Expected } \\
\text { PAYG } \\
\text { premium } \\
1-\frac{1+\nu}{1+r}\end{array}$} & \multirow[b]{2}{*}{$m p s$} & \multicolumn{2}{|c|}{$\begin{array}{l}\text { Conditions } \\
\text { for } \bar{\theta}>0\end{array}$} & \multicolumn{2}{|c|}{$\begin{array}{l}\text { Saving } \\
\text { rates }\end{array}$} & \multirow{2}{*}{$\begin{array}{c}\text { Condition } \\
\text { for higher } \\
\text { savings } \\
\bar{\theta}<\end{array}$} \\
\hline & $1+n$ & $1+g$ & $1+v$ & & & $\left|\frac{\operatorname{Cov}[\cdot]}{1+v}\right|$ & $\beta$ & $\frac{s_{t}^{l f} A_{t}}{w A_{t}}$ & $\frac{s_{t} A_{t}}{w A_{t}}$ & \\
\hline \multicolumn{11}{|c|}{ baseline } \\
\hline $\begin{array}{l}3.3336 \\
1.0350\end{array}$ & $\begin{array}{l}1.1907 \\
1.0050\end{array}$ & $\begin{array}{l}1.1907 \\
1.0050\end{array}$ & $\begin{array}{l}1.4178 \\
1.0100\end{array}$ & 0.575 & 0.41 & 0.52 & 0.72 & 0.18 & 0.31 & 0.32 \\
\hline $\begin{array}{l}3.3336 \\
1.0350\end{array}$ & $\begin{array}{l}1.1907 \\
1.0050\end{array}$ & $\begin{array}{c}1.0000 \\
\mathbf{1 . 0 0 0 0}\end{array}$ & $\begin{array}{l}1.1907 \\
1.0050\end{array}$ & 0.643 & 0.41 & 0.47 & 0.64 & 0.18 & 0.27 & 0.24 \\
\hline $\begin{array}{l}3.3336 \\
1.0350\end{array}$ & $\begin{array}{l}1.1907 \\
1.0050\end{array}$ & $\begin{array}{c}1.0913 \\
1.0025\end{array}$ & $\begin{array}{l}1.2995 \\
1.0075\end{array}$ & 0.610 & 0.41 & 0.49 & 0.67 & 0.18 & 0.29 & 0.27 \\
\hline $\begin{array}{l}3.3336 \\
1.0350\end{array}$ & $\begin{array}{l}1.1907 \\
1.0050\end{array}$ & $\begin{array}{c}1.4166 \\
\mathbf{1 . 0 1 0 0}\end{array}$ & $\begin{array}{l}1.6868 \\
1.0151\end{array}$ & 0.494 & 0.41 & 0.61 & 0.83 & 0.18 & 0.36 & 0.44 \\
\hline $\begin{array}{l}3.3336 \\
1.0350\end{array}$ & $\begin{array}{l}1.1907 \\
1.0050\end{array}$ & $\begin{array}{c}1.6839 \\
\mathbf{1 . 0 1 5 0}\end{array}$ & $\begin{array}{l}2.0050 \\
1.0201\end{array}$ & 0.399 & 0.41 & 0.75 & 1.03 & 0.18 & 0.44 & 0.65 \\
\hline $\begin{array}{c}2.3732 \\
\mathbf{1 . 0 2 5 0}\end{array}$ & $\begin{array}{l}1.1907 \\
1.0050\end{array}$ & $\begin{array}{l}1.1907 \\
1.0050\end{array}$ & $\begin{array}{l}1.4178 \\
1.0100\end{array}$ & 0.403 & 0.58 & 1.05 & 1.44 & 0.18 & 0.44 & 0.45 \\
\hline $\begin{array}{c}2.8139 \\
\mathbf{1 . 0 3 0 0}\end{array}$ & $\begin{array}{l}1.1907 \\
1.0050\end{array}$ & $\begin{array}{l}1.1907 \\
1.0050\end{array}$ & $\begin{array}{l}1.4178 \\
1.0100\end{array}$ & 0.496 & 0.50 & 0.72 & 1.00 & 0.18 & 0.36 & 0.37 \\
\hline $\begin{array}{c}3.9461 \\
1.0400\end{array}$ & $\begin{array}{l}1.1907 \\
1.0050\end{array}$ & $\begin{array}{l}1.1907 \\
1.0050\end{array}$ & $\begin{array}{l}1.4178 \\
1.0100\end{array}$ & 0.641 & 0.33 & 0.40 & 0.52 & 0.17 & 0.26 & 0.28 \\
\hline $\begin{array}{c}4.6673 \\
\mathbf{1 . 0 4 5 0}\end{array}$ & $\begin{array}{l}1.1907 \\
1.0050\end{array}$ & $\begin{array}{l}1.1907 \\
1.0050\end{array}$ & $\begin{array}{l}1.4178 \\
1.0100\end{array}$ & 0.696 & 0.26 & 0.31 & 0.38 & 0.16 & 0.23 & 0.26 \\
\hline
\end{tabular}

Table 4: The equilibrium with quadratic preferences $\left(a_{t}=1 / w A_{t}\right)$ Sensitivity analysis of the rate of time preference and the expected retirement length

\begin{tabular}{|c|c|c|c|c|c|c|c|c|c|c|c|}
\hline \multicolumn{4}{|c|}{$\begin{array}{c}\text { Interest and growth rates } \\
\text { per period }\left(T_{1}=35 \text { years }\right) \\
\text { annual }\end{array}$} & \multirow{2}{*}{$\begin{array}{c}\text { Rate } \\
\text { time } \\
\text { pref. } \\
\rho\end{array}$} & \multirow{2}{*}{$\begin{array}{c}\text { Exp. } \\
\text { Retir. } \\
\text { length } \\
T_{2} / T_{1}\end{array}$} & \multirow[b]{2}{*}{$m p s$} & \multicolumn{2}{|c|}{$\begin{array}{l}\text { Conditions } \\
\text { for } \bar{\theta}>0\end{array}$} & \multicolumn{2}{|c|}{$\begin{array}{l}\text { Saving } \\
\text { rates }\end{array}$} & \multirow{2}{*}{$\begin{array}{c}\text { Cond. } \\
\text { higher } \\
\text { savings } \\
\bar{\theta}<\end{array}$} \\
\hline $1+r$ & $1+n$ & $1+g$ & $1+v$ & & & & $\left|\frac{\operatorname{Cov}[\cdot]}{1+v}\right|$ & $\beta$ & $\frac{s_{t}^{l f} A_{t}}{w A_{t}}$ & $\frac{s_{t} A_{t}}{w A_{t}}$ & \\
\hline $\begin{array}{c}3.33 \\
1.035\end{array}$ & $\begin{array}{l}1.19 \\
1.005\end{array}$ & $\begin{array}{l}1.19 \\
1.005\end{array}$ & $\begin{array}{c}1.42 \\
1.010\end{array}$ & 0.3 & 1.00 & 0.23 & 0.52 & 0.40 & 0.23 & 0.40 & 0.74 \\
\hline $\begin{array}{c}3.33 \\
1.035\end{array}$ & $\begin{array}{c}1.19 \\
1.005\end{array}$ & $\begin{array}{c}1.19 \\
1.005\end{array}$ & $\begin{array}{c}1.42 \\
1.010\end{array}$ & 0.3 & $\begin{array}{c}0.29 \\
(10 / 35)\end{array}$ & 0.51 & 0.52 & 0.89 & 0.15 & 0.25 & 0.21 \\
\hline $\begin{array}{c}3.33 \\
1.035\end{array}$ & $\begin{array}{c}1.19 \\
1.005\end{array}$ & $\begin{array}{c}1.19 \\
1.005\end{array}$ & $\begin{array}{c}1.42 \\
1.010\end{array}$ & 0.7 & $\begin{array}{c}0.43 \\
(15 / 35)\end{array}$ & 0.23 & 0.52 & 0.40 & 0.23 & 0.40 & 0.74 \\
\hline $\begin{array}{c}3.33 \\
1.035\end{array}$ & $\begin{array}{c}1.19 \\
1.005\end{array}$ & $\begin{array}{c}1.19 \\
1.005\end{array}$ & $\begin{array}{c}1.42 \\
1.010\end{array}$ & 0.5 & $\begin{array}{c}0.43 \\
(15 / 35)\end{array}$ & 0.30 & 0.52 & 0.51 & 0.21 & 0.37 & 0.53 \\
\hline
\end{tabular}


Table 5: The equilibrium with quadratic preferences (baseline values)

Sensitivity analysis of the PAYG rate

\begin{tabular}{lllllllllll}
\hline \multicolumn{10}{c}{$\begin{array}{c}\text { PAYG rates (from 0 to 0.39) } \\
\text { and the resulting saving rates }\end{array}$} \\
\hline \hline \\
\hline 0.00 & 0.01 & 0.02 & 0.03 & 0.04 & 0.05 & 0.06 & 0.07 & 0.08 & 0.09 \\
0.31 & 0.30 & 0.30 & 0.29 & 0.29 & 0.29 & 0.28 & 0.28 & 0.27 & 0.27 \\
& 0.10 & 0.11 & 0.12 & 0.13 & 0.14 & 0.15 & 0.16 & 0.17 & 0.18 & 0.19 \\
0.27 & 0.26 & 0.26 & 0.25 & 0.25 & 0.25 & 0.24 & 0.24 & 0.23 & 0.23 \\
0.20 & 0.21 & 0.22 & 0.23 & 0.24 & 0.25 & 0.26 & 0.27 & 0.28 & 0.29 \\
0.22 & 0.22 & 0.22 & 0.21 & 0.21 & 0.20 & 0.20 & 0.20 & 0.19 & 0.19 \\
& 0.30 & 0.31 & 0.32 & 0.33 & 0.34 & 0.35 & 0.36 & 0.37 & 0.38 & 0.39 \\
0.18 & 0.18 & 0.18 & 0.17 & 0.17 & 0.16 & 0.16 & 0.15 & 0.15 & 0.15 \\
& & & & & & & & & \\
\hline \hline
\end{tabular}

\section{References}

Bernheim, B. Douglas (2002) Taxation and Saving. In Handbook of Public Economics Vol. 3., ed. Alan J. Auerbach and Martin Feldstein. Amsterdam, London and New York: Elsevier Science, North-Holland.

Blanchard, Olivier J. and Stanley Fisher (1989) Lectures on Macroeconomics. 10th ed. Cambridge, Mass. and London: The MIT Press.

Bohn, Henning (1998). Risk Sharing in a Stochastic Overlapping Generations Economy. Working Paper wp3'98. Department of Economics, University of California at Santa Barbara, 1-44.

Bohn, Henning (2009). Intergenerational Risk Sharing and Fiscal Policy. Journal of Monetary Economics, 56: 805-816.

Borgmann, Christoph (2005) Social Security, Demographics, and Risk, Series: Population Economics. Berlin: Springer.

Demange, Gabrielle (2002) On Optimality in Intergenerational Risk Sharing. Economic Theory 20: 1-27.

De Menil George, Fabrice Murtin and Eytan Sheshinski (2005) Planning for the optimal mix of paygo tax and funded savings. Journal of Pension Economics and Finance, vol. $5(1), 1-25$.

Diamond, Peter A. (1965) National Debt in a Neoclassical Growth Model. American Economic Review 55 (5): 1126-1150.

Enders, Walter. and Harvey. E. Lapan (1982) Social Security Taxation and Intergenerational Risk Sharing. International Economic Review Vol. 23, No. 3: 647-658.

Feldstein, Martin. (1974) Social Security, Induced Retirement, and Aggregate Capital Accumulation. Journal of Political Economy 82 (5): 905-26.

Geanakoplos, John. (1987) Overlapping Generations Model of General Equilibrium. In The New Palgrave: A Dictionary of Economics Vol. 3., ed. John Eatwell, Murray Milgate and Peter Newman. Palgrave Macmillan.

Gordon, Roger H. and Hal R.Varian (1988) Intergenerational Risk Sharing. Journal of Public Economics 37: 185-202.

Heijdra, Ben J. and Frederick van der Ploeg (2002) Foundations of Modern Macroeconomics. Oxford: Oxford University Press. 
Homburg, Stefan. (1991) Interest and Growth in an Economy with Land. Canadian Journal of Economics, Canadian Economics Association, vol. 24(2): 450-59.

Kaul, Ashok (2001) Insurance Aspects of Social Security. PhD diss., University of Bonn.

Kohl, Richard and Paul O'Brien (1998) The Macroeconomics of Ageing, Pensions and Savings: a Survey. Economics Department Working Paper No. 200. OECD.

Matsen, Egil and Øystein Thøgersen (2004) Designing social security - a portfolio choice approach. European Economic Review, 48: 883-904 .

McCallum, Bennett T. (1987) The Optimal Inflation Rate in an Overlapping-Generations Economy with Land. In New approaches to monetary economics: Proceedings of the Second International Symposium in Economic Theory and Econometrics. International Symposia in Economic Theory and Econometrics series Cambridge. New York and Melbourne: Cambridge University Press.

Merton, Robert C. (1983) On the role of social security as a means for efficient risk sharing in an economy where human capital is not tradable. In: Financial Aspects of the United States Pension System, ed. Zvi Bodie and John B. Shoven. The University of Chicago Press.

Munnell, Alicia H. (2004) A Bird's Eye View of the Social Security Debate. An Issue in Brief Number 25. Center for Retirement Research at Boston College.

Persson, Torsten (1985) Deficits and Intergenerational Welfare in Open Economies. Journal of International Economics 19: 67-84.

Rangel, Antonio and Richard Zeckhauser (2001) Can Market and Voting Institutions Generate Optimal Intergenerational Risk Sharing?. In Risk Aspects of Investment-Based Social Security Reform, ed. John Y. Campbell and Martin Feldstein. Conference report (National Bureau of Economic Research). Chicago: The University of Chicago Press.

Richter, Wolfram F. (1993) Intergenerational risk sharing and social security in an economy with land. In Public Pension Economics, ed. Bernhard Felderer. Vienna, New York: Springer-Verlag.

Samuelson, Paul A. 1958. An Exact Consumption-Loan Model of Interest with or without the Social Contrivance of Money. Journal of Political Economy Vol. 66, No.6: 467-482.

Thфgersen, Øysten. (1998) A Note on Intergenerational Risk Sharing and the Design of Pay-As-You-Go Pension Programs. Journal of Population Economics 11: 373-378.

Thфgersen, Øysten and Kine Bøhlerengen (2010) Alternative Risk-Sharing Mechanisms of Social Security. FinanzArchiv/Public Finance Analysis, 66: 134-152.

Wagener, Andreas (2003) Pensions as a portfolio problem: fixed contribution rates vs. fixed replacement rates reconsidered. Journal of Population Economics, 16: 111-134. 